\title{
Dead Sea Starvation: Towards Enhanced Monitoring of Water Resources by Modeling Meteorological Variables and Remote Sensing Data
}

\author{
Nazeeh Ghatasheh1, Ismail Al-Taharwa², Bilal Al-Ahmad², Mua'ad Abu-Faraj² \\ ${ }^{1}$ Department of Business Information Technology, The University of Jordan, Aqaba, Jordan \\ ${ }^{2}$ Department of Computer Information Systems, The University of Jordan, Aqaba, Jodan \\ Email:n.ghatasheh@ju.edu.jo,i_taharwa@ju.edu.jo,b.alahmad@ju.edu.jo,m.abufaraj@ju.edu.jo
}

How to cite this paper: Ghatasheh, N., Al-Taharwa, I., Al-Ahmad, B. and AbuFaraj, M. (2016) Dead Sea Starvation: Towards Enhanced Monitoring of Water Resources by Modeling Meteorological Variables and Remote Sensing Data. Journal ot Software Engineering and Applications, 9, 588-600.

http://dx.doi.org/10.4236/jsea.2016.912040

Received: October 25, 2016

Accepted: December 27, 2016

Published: December 30, 2016

Copyright $\odot 2016$ by authors and Scientific Research Publishing Inc. This work is licensed under the Creative Commons Attribution International License (CC BY 4.0).

http://creativecommons.org/licenses/by/4.0/

(c) (i) Open Access

\begin{abstract}
Meteorological metrics have been used for weather forecasting and climate prediction. Remote sensing images proved to be a valuable resource to represent the terrain of earth's surface. Recently, there has been extensive research to model changes on the earth's landscape including water bodies using remote sensing images. Meanwhile, meteorological data have been used mainly to model climate changes. This research tries to leverage both resources to achieve enhanced monitoring of the Dead Sea shrinkage: first, an attempt to model the relation between several meteorological variables and Dead Sea shrinkage using machine learning; second, formulating Dead Sea shrinkage in terms of water level and surface area using data extraction from remote sensing images; finally, confronting the two models to derive a novel approach for predicting Dead Sea shrinkage based on spatio-temporal images and meteorological measures. The main machine learning algorithms for modeling the water shrinkage in this empirical research are Decision Table, Linear Regression, and Multi Layer Perceptron Neural Networks. The Mean Absolute Error measure of the best model is 1.743 and 0.015 . It is challenging to model the relation between meteorological variables and the water level. However, the obtained results are promising to formulate a model of the water level decline rate, which in its turn will be an essential tool for estimating the consumption limits and inflow needs to save the Dead Sea.
\end{abstract}

\section{Keywords}

Analytics, Dead Sea, Machine Learning, Meteorological Modeling, Remote Sensing, Risk Prediction 


\section{Introduction}

The Dead Sea is considered as the earth's lowest elevation with more than 400 meters below sea level (mbsl) as well as the world's saltiest waterbody. It is located in Jordan Rift Valley, the Middle East. The Dead Sea has cultural, economic, and historical importance locally and globally. One of the most economical values of Dead Sea is its huge content of potash and bromine. The Dead Sea is shrinking at a very high rate. Scientists started to monitor the Dead Sea levels in the 1950s. It has been studied by different researchers to calculate and estimate its declining rate; some of the researchers have estimated a declining rate between 0.9 and 1.5 meters annually [1].

According to the study [2], the Dead Sea has special environmental conditions that rapidly change over the years, as the water level is continuously decreasing. From 1960 to 2012, the Dead Sea water level declined approximately from $394 \mathrm{mbsl}$ to $423 \mathrm{mbsl}$. These days, the Dead Sea area of water surface has been roughly decreased from 950 $\mathrm{km}^{2}$ to $637 \mathrm{~km}^{2}$. One of the possible declining factors is the established fertilizer companies on the sides of the Dead Sea that consume part of the waterbody. The different industries of fertilizing that benefit from the Dead Sea water by extracting processes have negative impact on the Dead Sea.

There are many reasons which led to the degradation of the Dead Sea as pumping water from Jordan River to irrigate crops in the Jordan Valley instead of feeding the Dead Sea, and the poor rainy seasons of the past decades [1] [2]. The Dead Sea also has an economical importance not just because of its value as tourist attraction point, but also for its huge content of salts (e.g., potash and bromine). Such importance makes water declining rate of the Dead Sea an economical threat for the beneficiary countries. The critical situation and crucial role of the Dead Sea in the region call for immediate actions to save it.

Satellites have many uses nowadays; one of these many uses is viewing the surface of the earth, which allows scientists to collect different kinds of information about the earth's surface. A single satellite image can show the spread of oil spill into ocean, the damage done by hurricane, the spread of desertification into a certain forests and many other changes [3] [4]. Additionally, satellite imagery has applications in different military and civil fields as Global Positioning Systems (GPS), ocean currents and temperatures, monitoring pollution, and many other applications [5] [6] [7] [8] [9].

This study essentially used a machine learning based approach which combines both of several meteorological variables and remote sensing data in order to improve the detection of possible causes for the Dead Sea shrinkage. Accordingly, all input variables and measures were analyzed experimentally using different machine learning approaches. The experiments aim to discover several waterbody shrinkage models for the Dead Sea by comparing the association between water level and several related meteorological variables.

\section{Related Work}

Different research studies have applied several approaches to examine various geome- 
trical aspects of the Dead Sea, i.e., water level, weather prediction, etc. In [10], the research study shows the result of applying three Matlab image-processing functions on the Dead Sea satellite images which have been taken from Google Timelapse. The three functions are: edge-based, threshold and watershed segmentation. The study specified the edges of the Dead Sea using image processing functions to predict decreasing rate of the Dead Sea.

In [11], researchers used remote sensing images of the Dead Sea to estimate the water surface decline over the period 1810-2005. According to spatial analysis, the decline was about $20 \mathrm{~m}$ and the surface area in the 2004 reached $640.62 \mathrm{~km}^{2}$. This study included an effective analysis on images from several sources for the years 1973, 1983, and 2004 respectively. Afterwards the three images geometry was modified by edge enhancement routine. Moreover the images were manipulated to remove atmospheric effects. Finally an overlay analysis identified the reduction of the waterbody. In regard to the water level the researchers used historical data as well as a few measurements using Global Positioning System. They noticed an increase to the water level in the years 1991-1992 due to the excessive water inflows in that period. Their survey recordings of water levels in the years 2005 and 2006 were about $-416 \mathrm{~m}$ and $-417 \mathrm{~m}$ correspondingly. A remark stated that the water level measurements were applied after rainfall periods which reflected in the homogeneity of results. They concluded that the waterbody of the Dead Sea is declining over time.

Based on the investigation of the research study in [12], there are several reasons for the decline of the Dead Sea water level, e.g., inflows shortage, natural evaporation, potash companies' consumption, and salt production. Based on their model the Dead Sea is estimated to decline from $411 \mathrm{mbsl}$ level in 1997 to $479 \mathrm{mbsl}$ in 2007. Furthermore, they tried to come up with different approaches to detect the Dead Sea fluctuations in terms of water level and volume. They pointed to their efforts in checking the duration time that would be needed to mix the inflows with the existing waterbody. Their two main proposed models to identify the mixing time for the changes in sea level and surface area named as "single-layer" and "two-layer" Dead Sea models.

Similarly like the Dead Sea, the Aral Sea, found between Kazakhstan and Uzbekistan has been explored by different studies in order to understand the water level shrinkage. The research study in [13] focused on the shared attributes between the two seas with respect to the dramatic decline and properties. Over centuries both seas faced dangerous water volume loss that required serious attention. The interesting changes in minerals concentrations in both waterbodies bring significant environmental and economic concerns to support water management efforts. In [9], the authors provide more different approaches to find declining rate and estimate surface area, these approaches have low operational cost and time complexity; however some of these results suffer from noise.

Other research studies focused on using image segmentation technique to satisfy different purposes onto visual measurements. For example, the study [14] used Clone Clustering Algorithm (DICCA) by merging both texture image segmentation and fea- 
ture extraction for measuring the water/land combination. Boulila et al. [15] in their study used Case-Based Reasoning (CBR) method by integrating knowledge discovery and environmental features in order to simulate human reasoning about spatiotemporal changes. Many of the investigated studies used image processing techniques or inferences from historical events to describe the decline of the Dead Sea. However, none of the Dead Sea waterbody studies pointed to the use of Machine Learning approaches to predict or model the related factors.

\section{Data and Methodology}

The work done in this research combines several data resources into simplified datasets. Afterwards, the computer intelligence analyzes the datasets to create prediction models. The following subsections describe the consolidated datasets, the used machine learning algorithms, and the experiments setup:

\subsection{Datasets}

The empirical results of this research rely on two main datasets; 1) The first dataset (DS1) was consolidated from several sources [9] [16] [17] [18] [19], 2) the second dataset (DS2) consists of several meteorological variables and waterbody measures. The variables of the first and the second datasets are described in Table 1 and Table 2 respectively. Level drop in meters is calculated using Equation (1) which represents the shrinkage of the Dead Sea. There are no missing values in the first dataset, while averaging of the values in the second dataset filled the missing values. In the appendix, Figure A1 and Figure A2 illustrate the values of the variables in the first and second dataset respectively.

Table 1. First Dataset (DS1) feature set description.

\begin{tabular}{cc}
\hline Characteristic & Description and Specifications \\
\hline No. Instances & 11 \\
Period & $1984-1994$ \\
DSLM & Dead Sea Water Level in Meters, below sea level \\
Area Km ${ }^{2}$ & Water Surface Area in Km ${ }^{2}$ \\
JRS_DisM & \\
InFlowM & Jordan River summer discharges in Mio $\mathrm{m}^{3}$ \\
GorSafi_Rain & Ground and surface inflows into the Dead Sea in Mio $\mathrm{m}^{3}$ \\
DeirAlla_Rain & Average rain over GorSafi area (Near Dead Sea) \\
PRE-ANN & Average rain over DeirAlla area (Near Dead Sea) \\
TMP-ANN & Precipitation in millimetres per month, annual average for Jordan \\
CLD-ANN & Daily mean temperature in degrees Celsius, annual for Jordan \\
PET-ANN & Cloud Cover Percentage (\%), annual for Jordan \\
Missing Values & Potential Evapo Transpiration in millimetres per day, annual for Jordan \\
\hline
\end{tabular}


Table 2. Second Dataset (DS2) feature set description.

\begin{tabular}{cc}
\hline Characteristic & Description and Specifications \\
\hline No. Instances & 18 \\
Period & $1992-2009$ \\
Water Temp & Water temperature \\
Air Temp & Air temperature \\
Relative Humidity & Relative humidity \\
Solar Radiation & Solar radiation \\
LWR & LWR net (emit-atm) $\left(\mathrm{W} / \mathrm{m}^{2}\right)$ \\
Bowen Ratio & Browen ratio \\
Evaporation WM ${ }^{2}$ & Evaporation in W/M $\mathrm{M}^{2}$ \\
Evaporation Wr & Evaporation in W/Year \\
Total Inflows & Total inflows \\
Level_mbsl & Level below sea level in meters \\
Level Dropm & Level drop in meters \\
Area Km ${ }^{2}$ & Water surface area in Km ${ }^{2}$ \\
Missing values & 2002-2004 \\
\hline
\end{tabular}

${ }^{a}$ Water Temp, Air Temp, Relative Humidity, Solar Radiation, LWR, Bowen Ratio, Qn-Qad, Evaporation WM².

$$
\text { Level Drop }=\left(\text { Level_ mbsl }{ }_{\text {year }(i)}\right)-\left(\text { Level_ } \text { mbsl }_{\text {year }(i-1)}\right)
$$

Even though meteorological variables are the main contributors in both DS1 Table 1 and DS2 Table 2, there are significant variations between the two datasets. While the Level_mbsl and Area $\mathrm{Km}^{2}$ features in DS2 Table 2 are actual measurements gathered by geology and meteorology scientists. The DSLM and Area $\mathrm{Km}^{2}$ features in DS1 Table 1 were calculated and derived using polynomial equations applied to remote sensing images [17]. Interestingly, such variation in data sources has two merits. First, it allows for reliable prediction of Dead Sea surface drop rate. Second, it provides a mean to evaluate work done in literature based on remote sensing images.

\subsection{Machine Learning Algorithms}

Literature discusses a range of machine learning techniques that have been used for model construction. Among those, prediction techniques of supervised learning are the most appropriate to handle the problem of Dead Sea water surface shrinkage rate. The problem is demonstrated to be supervised since training data have been made available with an empirically measured target variable. Furthermore, the issue is prediction problem since the target variable is continuous (i.e., level Drop, level_mbsl, and DLSM variables are all continuous variables). In particular, Decision Tree (DT), Linear Regression (LR), and Multi-Layer Perceptron (MLP) techniques have been chosen to model the problem of Dead Sea shrinkage rate.

Multi-Layer Perceptron is a neural network implementation that is commonly used to extract and model complex patterns and trends. MLP leverages backward and forward chaining to optimize the weights given to the independent variables. MLP has 
been proven to deal with complex problems, there main issue is the relatively long training time. However, in our case, the problem dimensionality is relatively low, which makes MLP a preferred option to model Dead Sea shrinkage rate. On the other hand, DT leverages entropy measurements to build rule-based models that are very intuitive and easy to explain \& implement.

LR encompasses large range of mathematical models that have been extensively used and proven to deal with a wide range of problems. It is based on the concept of error minimization. The key issue with LR is the possibility to fall into a local-optima instead of catching the global one. However, simplicity and scalability of the LR model make it a preferred choice when convenience is required. Two variations of LR models have been constructed and tested in this work. First, regular linear regression model that maintains all independent variables in the feature vector. Second, linear regression model with feature selection. This variation applies feature selection to eliminate irrelevant features. Thus, instead of dealing with all features in the feature vector, it confines itself with those most prominent features (i.e., a subset of the feature set). So far, LR_All, and LR will be used to refer to the former and the latter variations respectively.

\subsection{Experiments}

There are two sets of experiments, (a) Modeling the Dead Sea shrinkage from DS1 using the three machine learning algorithms, (b) Applying the same algorithms on DS2 to model the shrinkage. In each of the sets (a) \& (b), "Best First" attribute selection method tries to eliminate the less significant attributes before model building. Each of the sets (a) \& (b) undergo through 5 -fold cross validation. The best performing algorithms over the datasets are selected and reported. Table 3 shows the settings of the algorithms. Table 4 shows performance evaluation metrics. All the experiments were

Table 3. Machine learning models to predict Dead Sea water-level drop (level Dropm).

\begin{tabular}{|c|c|c|}
\hline Model & Algorithm & Settings \\
\hline DT-DS1 & Decision Table & $\begin{array}{l}\text { Scheme: weka.classifiers.rules. Decision Table-X 1-S } \\
\text { "weka.attributeSelection. Best First-D 1-N 5" }\end{array}$ \\
\hline LR-DS1 & Linear Regression & $\begin{array}{l}\text { Scheme: weka.classifiers.functions. Linear } \\
\text { Regression-S 0-R 1.0E-8 }\end{array}$ \\
\hline LR_All-DS1 & $\begin{array}{l}\text { Linear Regression, No } \\
\text { Attribute Selection }\end{array}$ & $\begin{array}{l}\text { Scheme:weka.classifiers.functions. Linear } \\
\text { Regression-S 1-R 1.0E-8 }\end{array}$ \\
\hline MLP-DS1 & Multi Layer Perceptron & $\begin{array}{l}\text { Scheme:weka.classifiers.functions. } \\
\text { Multilayer Perceptron-L 0.3-M 0.15-N 60-V 0-S 0-E 20-H } 2\end{array}$ \\
\hline DT-DS2 & Decision Table & $\begin{array}{l}\text { Scheme:weka.classifiers.rules. Decision Table-X 1-S } \\
\text { "weka.attributeSelection. Best First-D 1-N 5" }\end{array}$ \\
\hline LR-DS2 & Linear Regression & $\begin{array}{l}\text { Scheme:weka.classifiers.functions. Linear } \\
\text { Regression-S 0-R 1.0E-8 }\end{array}$ \\
\hline LR_All-DS2 & $\begin{array}{l}\text { Linear Regression, } \\
\text { No Attribute Selection }\end{array}$ & $\begin{array}{l}\text { Scheme:weka.classifiers.functions. } \\
\text { Linear Regression-S 1-R 1.0E-8 }\end{array}$ \\
\hline MLP-DS2 & Multi Layer Perceptron & $\begin{array}{c}\text { Scheme:weka.classifiers.functions. Multilayer Perceptron-L } \\
0.3-\mathrm{M} 0.2-\mathrm{N} 500-\mathrm{V} 0-\mathrm{S} 0-\mathrm{E} 20-\mathrm{H} \text { a }\end{array}$ \\
\hline
\end{tabular}


Table 4. Performance evaluation metrics.

\begin{tabular}{ccc}
\hline Metric & \multicolumn{1}{c}{ Description } & Equation \\
\hline CORR & CORRelation coefficient & \\
MAE & Mean Absolute Error & MAE $=\frac{1}{N} \sum_{i=1}^{n}\left|y_{i}-\hat{y}_{i}\right|$ \\
RMSE & Root Mean Squared Error & RMSE $=\sqrt{\frac{\sum_{i=1}^{n}\left(y_{i}-\hat{y}_{i}\right)^{2}}{n}}$ \\
RAE & Relative Absolute Error & $\mathrm{RAE}=\sum_{i=1}^{n} \frac{\left|y_{i}-\hat{y}_{i}\right|}{y_{i}}$ \\
RRSE & Root Relative Squared Error & $\mathrm{RRSE}=\sqrt{\frac{\sum_{i=1}^{n}\left(y_{i}-\hat{y}_{i}\right)^{2}}{\sum_{i=1}^{n}\left(y_{i}-\bar{y}_{i}\right)^{2}}}$ \\
Instances & Total Number of Instances \\
Attributes & Total Number of Input Variables & \\
\hline
\end{tabular}

configured and performed in the WEKA (Waikato Environment for Knowledge Analysis) which has been introduced by [20].

\section{Results and Discussion}

The main contribution of this research is applying machine learning approaches to model the Dead Sea Shrinkage. The related literature and studies does not offer similar documented methodology to be used as a benchmark. However, such models are expected to open the door for an emergent need to reliably monitor the Dead Sea shrinkage rate. It is challenging to draw the relation between meteorological variables and the Dead Sea water level. Among several experiments using various numbers of algorithms, the most promising results are discussed here. The performance of the best experimental results over the two datasets is illustrated in Figure 1 and Figure 2.

The approach of estimating the water level using the first dataset variables is highly challenging, it is noticeable how it is hard to find clear and highly accurate relation between the inputs and water level. Nonetheless, MLP model has the best performance in terms of prediction errors. Other results and attempts were not reported in this research as they did not outperform the results presented here. The omitted results include predicting the surface area and dimensionality reduction by variable selection and ranking. The analysis of the results proposes that there are hidden or missing factors affecting the water level drop. Possible contributors to the volume of the Dead Sea waterbody may include industrial consumption or the control over water inflows. It is not an easy task to obtain more input variables as some may be confidential or undisclosed by industrial institutions. But it would be worthwhile for further research to estimate the missing variables. The second approach used the second dataset to estimate the water level drop over the years. The performance of the selected algorithms is promising. Linear regression model outperformed the other models significantly, either using all 


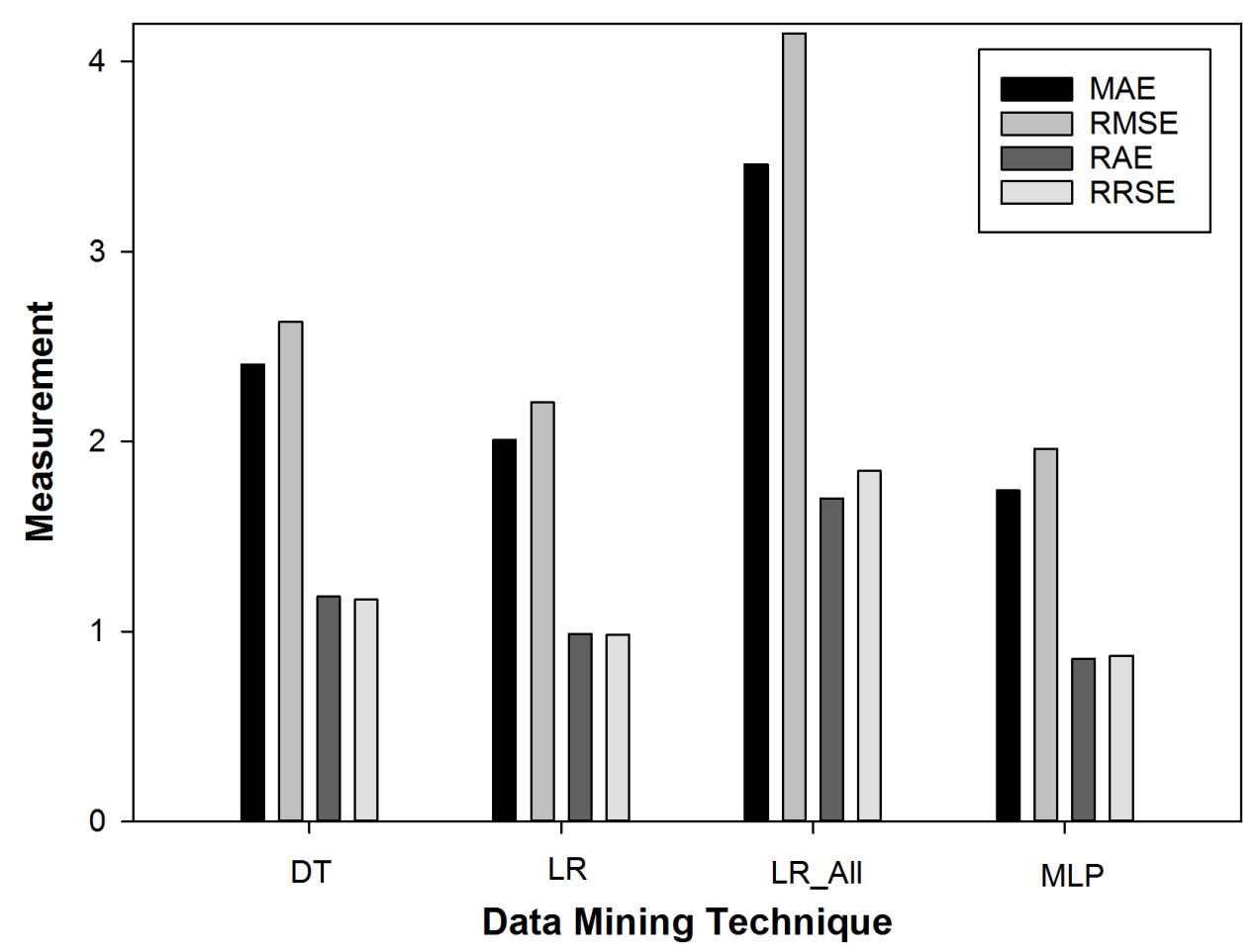

Figure 1. Performance of the selected algorithms over dataset 1.

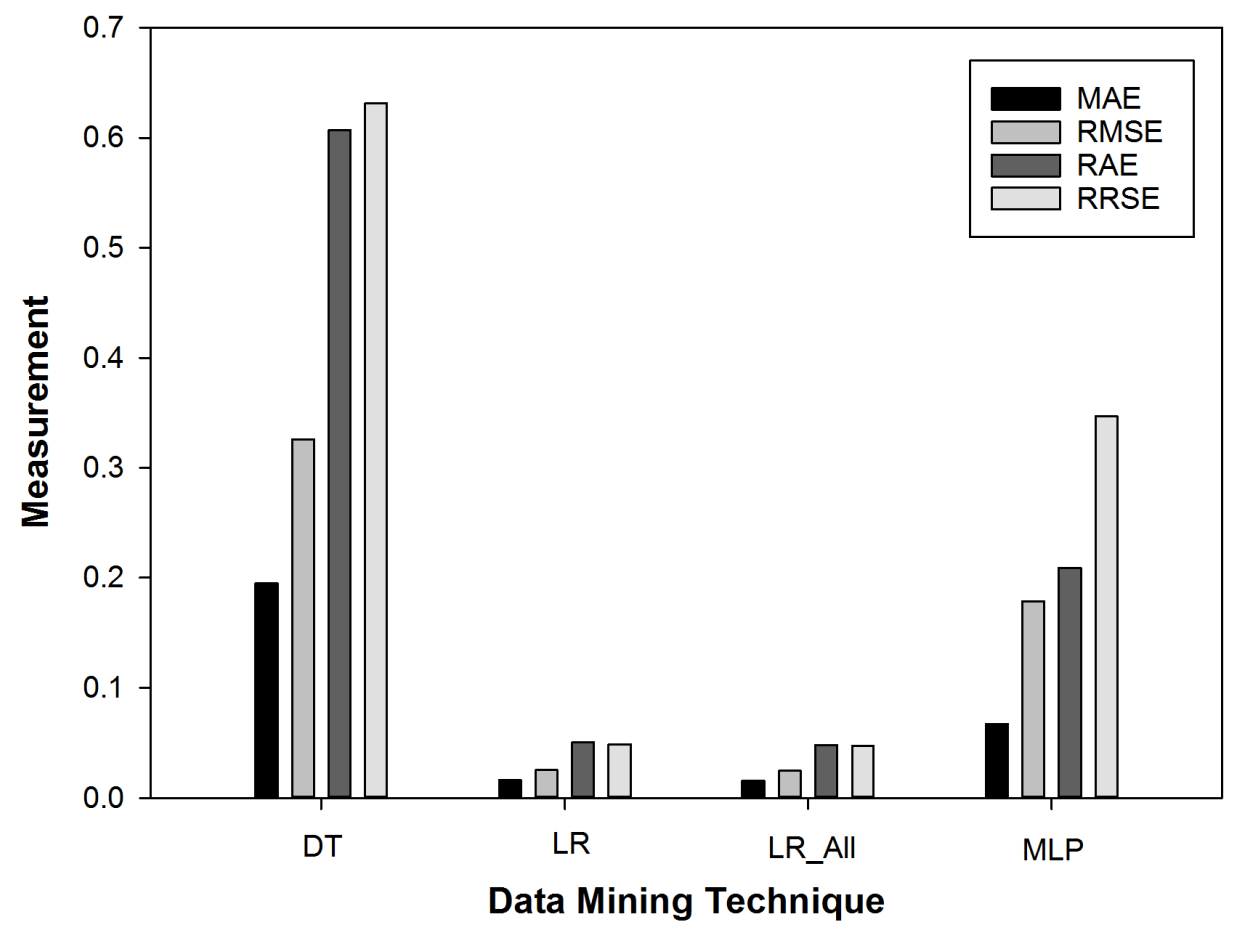

Figure 2. Performance of the selected algorithms over dataset 2.

input variables or by variable selection. The best generated linear regression models using all input variables and by variable selection are presented in Equation (2) and 
Equation (3) respectively. The models show the relationship between the various input variables and water level drop in meters. The most contributing variables found are the solar radiation, LWR, Bowen ratio and total water inflows.

$$
\begin{aligned}
\text { Level Dropm }= & (0.0809 * \text { Water Temp })-(0.0763 * \text { Air Temp }) \\
& +(0.0026 * \text { Relative Humidity })+(0.0102 * \text { Solar Radiation }) \\
& -(0.0224 * \text { LWR })-(1.6283 * \text { Bowen Ratio }) \\
& +(0 * \text { Evaporation WM })-(0.2858 * \text { Evaporation Wyr }) \\
& -(0.0015 * \text { TotalInflows })+1.3438 \\
\text { Level Dropm }= & (0.0079 * \text { SolarRadiation })-(0.0114 * \text { LWR }) \\
& -(0.9803 * \text { BowenRatio })-(0.0015 * \text { TotalInflows })+0.8534
\end{aligned}
$$

Figure 3 illustrates the performance comparison of the best model from each approach in building the Dead Sea models. While the exact performance measures are presented in Table 5 .

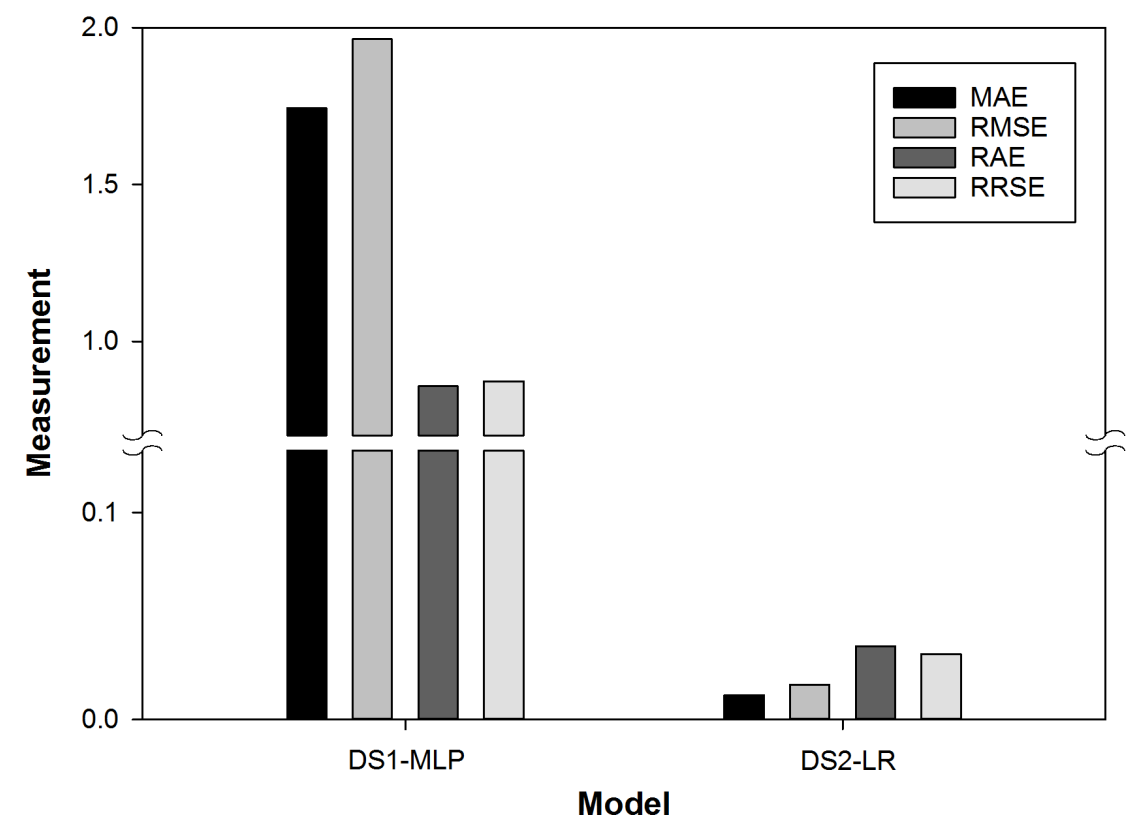

Figure 3. The best model of each dataset.

Table 5. Summary of the best results.

\begin{tabular}{ccc}
\hline Algorithm & LR_AllAtt & MLP \\
\hline Dataset & DS2 & DS1 \\
CORR & 0.999 & 0.652 \\
MAE & 0.0155 & 1.743 \\
RMSE & 0.0246 & 1.9633 \\
RAE & 4.813 & 85.695 \\
RRSE & 4.7558 & 87.2591 \\
Instances & 18 & 11 \\
Attributes & 10 & 9
\end{tabular}


The linear regression model from the second approach outperformed significantly the other models from the first approach. The main challenge in building the models in the two approaches is the limited access to reliable data. The second dataset contains a higher number of instances and input variables than the first dataset. Despite that, the overall number of instances is not sufficient to draw highly accurate conclusion of which is the most influential variables. On the other hand, data collection was an overwhelming task and the data came from several sources over different years. For example the meteorological variables for Jordan covered more than 100 years, while those for cities near the Dead Sea were very limited. Moreover, the precision of the collected data for some variables is unknown.

Based on the results, it is clear that there are similarities between the linear regression outputs regardless the use of feature selection. As a result, the reliability of the results is high. The role of feature selection in machine learning expedites the estimation, as well it enhances the correlation of the regression model, and reduces the confusion of results. Consequently, it is expected to have significant improvement when maintaining feature selection. Slight differences between the results prior to feature selection and after it indicates the right choice and high relevance of the feature set.

\section{Conclusion and Future Work}

This study explored the potentials of computer intelligence to enhance the discovery of possible causes for the Dead Sea starvation. Machine learning algorithms tried to enhance the monitoring of the waterbody by unveiling hidden relationships between various input variables. Meteorological variables and remote sensing datasets from different sources were analyzed experimentally. The experimental results led to formulating two models that represent the relationship between several variables and the Dead Sea water level. Modeling the shrinkage rate using meteorological variables and water flows outperformed the other models significantly. However, the task was challenging due to the difficulty in data collection. The overall conclusion shows that computer intelligence can contribute in the sustainable development of the Dead Sea. On the other hand, the datasets quality is essential for drawing precise results. Further future work intends to seek high quality datasets to leverage the accuracy of the developed models, which includes other factors as the industrial consumption.

\section{References}

[1] Nof, R.N., Ziv, A., Doin, M.-P., Baer, G., Fialko, Y., Wdowinski, S., Eyal, Y. and Bock, Y. (2012) Rising of the Lowest Place on Earth Due to Dead Sea water-Level Drop: Evidence from SAR Interferometry and GPS. Journal of Geophysical Research: Solid Earth, 117, 217 229. https://doi.org/10.1029/2011/B008961

[2] McPhail, S.L. (2016) Red Sea Dead Sea Water Conveyance Study Program Overview. http://siteresources.worldbank.org

[3] Office of the Maritime Administrator (2011) Deepwater Horizon Marine Casualty Investigation Report. http://www.register-iri.com

[4] Verón, S.R., Paruelo, J.M. and Oesterheld, M. (2006) Assessing Desertification. Journal of 
Arid Environments, 66, 751-763. https://doi.org/10.1016/j.jaridenv.2006.01.021

[5] Muresan, O., Pop, F., Gorgan, D. and Cristea, V. (2006) Satellite Image Processing Applications in MedioGRID. Proceedings of the Fifth International Symposium on Parallel and Distributed Computing, Timisoara, 6-9 July 2006, 253-262.

[6] Gorgan, D., Bacu, V., Stefanut, T., Rodila, D. and Mihon, D. (2009) Grid Based Satellite Image Processing Platform for Earth Observation Application Development. IEEE International Workshop on Intelligent Data Acquisition and Advanced Computing Systems: Technology and Applications, Renda, 21-23 September 2009, 247-252. https://doi.org/10.1109/idaacs.2009.5342987

[7] Wang, Z. and Pei, X. (2009) Application of Principal Component Extraction Technique in Processing Cloud Images from Chinese FY-1 Satellite. 2009 International Conference on Image Analysis and Signal Processing, Linhai, 11-12 April 2009, 18-21. https://doi.org/10.1109/IASP.2009.5054569

[8] Bharathi, S., Shreyas, V.J., Anirudh, R.P., Sanketh, S.M., Shenoy, P.D., Venugopal, K.R. and Patnaik, L.M. (2012) Performance Analysis of Segmentation Techniques for Land Cover Types Using Remote Sensing Images. 2012 Annual IEEE India Conference, Kochi, 7-9 December 2012, 775-780. https://doi.org/10.1109/INDCON.2012.6420721

[9] Abu-Faraj, M., Ghatasheh, N., Faris, H. and Harfoushi, O. (2014) Evaluation of Spatial Image Processing Approaches for Calculating Water Surface Area: Case of the Dead Sea. Life Science Journal, 11, 114-121.

[10] Abu-Faraj, M. and Ghatasheh, N. (2013) Using Image Processing Functions to Determine the Edges of the Dead Sea and Calculate the Declining Rate. International Journal of Computer Science Issues (IJCSI), 10, 97-101.

[11] Rawashdeh, S., Ruzouq, R., Al-Fugara, A., Biswajeet, P., Abu-Hamatteh, Z. and Abu Rumman, G. (2013) Monitoring of Dead Sea Watersurface Variation Using Multi-Temporal Satellite Data and GIS. Arabian Journal of Geosciences, 6, 3241-3248. https://doi.org/10.1007/s12517-012-0630-6

[12] Bashitialshaaer, R., Persson, K. and Aljaradin, M. (2011) The Dead Sea Future Elevation. International Journal of Sustainable Water and Environmental Systems, 2, 67-76.

[13] Oren, A., Plotnikov, I., Sokolov, S. and Aladin, N. (2010) The Aral Sea and the Dead Sea: Disparate Lakes with Similar Histories. Journal of Lakes \& Reservoirs. Research \& Management, 15, 223-236. https://doi.org/10.1111/j.1440-1770.2010.00436.x

[14] Ma, W., Ti, F., Li, C. and Jiao, L. (2013) Image Segmentation Based on Differential Immune Clone Clustering Algorithm. International Journal of Intelligent Computing and Cybernetics, 6, 83-102. https://doi.org/10.1108/17563781311301535

[15] Boulila, W., Farah, I.R., Solaiman, B. and Ben Ghézala, H. (2011) Interesting Spatiotemporal Rules Discovery: Application to Remotely Sensed Image Databases. VINE, 41, 167-191. https://doi.org/10.1108/03055721111134808

[16] Harris, I.P, Jones, P.D., Osborn, T.J. and Lister, D.H. (2014) Updated High-Resolution Grids of Monthly Climatic Observations-The CRU TS3.10 Dataset. International Journal of Climatology, 34, 623-642. https://doi.org/10.1002/joc.3711

[17] Ghatasheh, N., Mua'ad, M. and Faris, H. (2013) Dead Sea Water Level and Surface Area Monitoring Using Spatial Data Extraction from Remote Sensing Images. International Review on Computers and Software, 8, 2892-2897.

[18] Salameh, E. and El-Naser, H. (2000) Changes in the Dead Sea Level and Their Impacts on the Surrounding Groundwater Bodies. Acta Hydrochimica et Hydrobiologica, 28, 24-33. https://doi.org/10.1002/(SICI)1521-401X(200001)28:1<24::AID-AHEH24>3.0.CO;2-6 
[19] Abu-Sharar, T.M., Semawi, M. and Wilhite, D. (2014) Drought Conditions and Management Strategies in Jordan. Initiative on Capacity Development to Support National Drought Management Policies Workshop, Cairo. http://www.ais.unwater.org/ais/pluginfile.php/605/mod page/content/23/Jordan.pdf

[20] Hall, M., Frank, E., Holmes, G., Pfahringer, B., Reutemann, P. and Witten, I.H. (2009) The WEKA Data Mining Software: An Update. ACM SIGKDD Explorations Newsletter, 11, 10-18. https://doi.org/10.1145/1656274.1656278 


\section{Appendix}

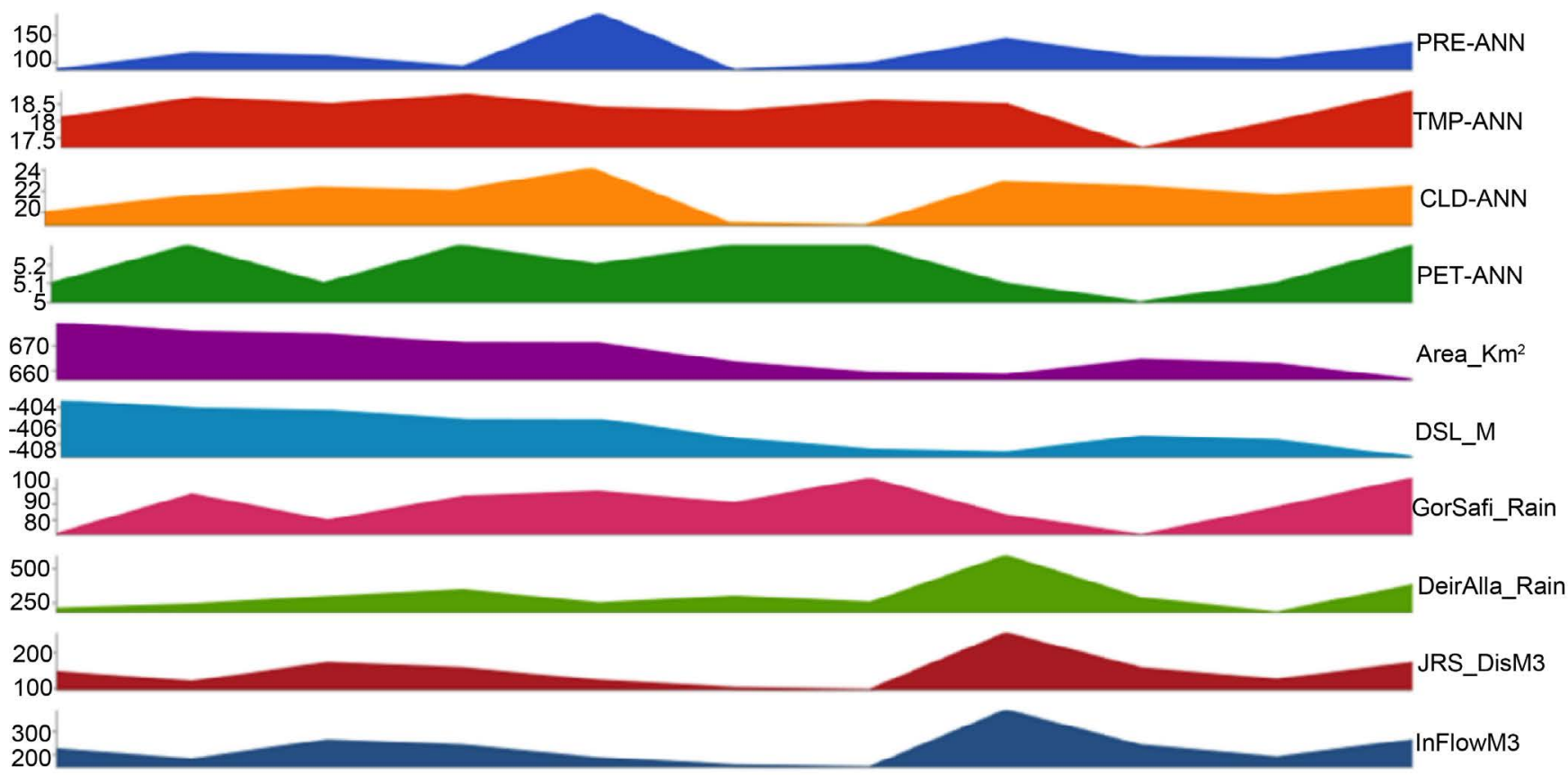

Figure A1. First dataset variables for the period 1984-1994.

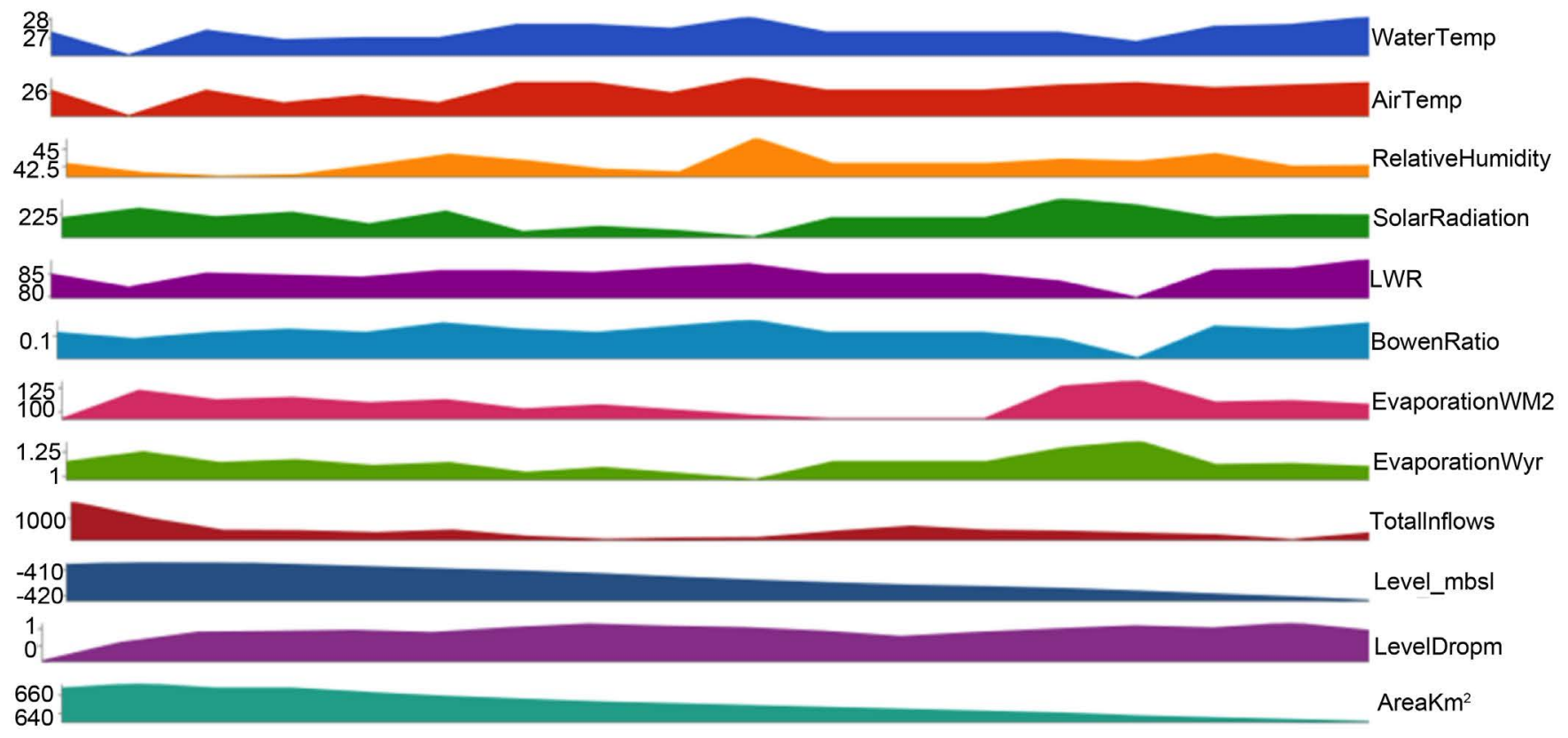

Figure A2. Second dataset variables for the period 1992-2009. 
Submit or recommend next manuscript to SCIRP and we will provide best service for you:

Accepting pre-submission inquiries through Email, Facebook, LinkedIn, Twitter, etc.

A wide selection of journals (inclusive of 9 subjects, more than 200 journals)

Providing 24-hour high-quality service

User-friendly online submission system

Fair and swift peer-review system

Efficient typesetting and proofreading procedure

Display of the result of downloads and visits, as well as the number of cited articles

Maximum dissemination of your research work

Submit your manuscript at: http://papersubmission.scirp.org/

Or contact jsea@scirp.org 